\title{
Combined excision-ablation laparoscopic surgery in large ovarian endometrioma
}

\author{
Original Ayman A. EI-Dorf', Hesham M. Borg', Ahmed M. E. Ossman ${ }^{1}$, Hesham A. Salem , \\ Article Mahmoud A. El Hamedi \\ ${ }^{1}$ Department of Obstetrics and Gynaecology, Faculty of Medicine, Tanta University, Egypt \\ ${ }^{2}$ Department of Obstetrics and Gynaecology, Faculty of Medicine, Zawia University, Libya
}

\begin{abstract}
Objective: To evaluate the effect of laparoscopic treatment of large ovarian endometrioma $>3 \mathrm{~cm}$ by two modalities ; namely, cystectomy and a combination of partial cystectomy with ultrasound power, ablation on the ovarian reserve and recurrence.

Method: A prospective randomized clinical study at Obstetrics and Gynecology Department at Tanta University Hospital, Egypt, included 40 women less than 35 years with large ovarian endometrioma $>3 \mathrm{~cm}$ complaining of infertility and/or pelvic pain with no previous history of medical or surgical treatment of endometriosis. These patients were randomized for either laparoscopic complete cystectomy (Cystectomy group; 20 patients) or partial cystectomy combined with ultrasound power ablation (Combined group, 20 patients). Main outcome measures included the changes in levels of AMH. Basal serum levels of FSH and LH, and AFC before laparoscopy and six months later. Recurrence and spontaneous pregnancy rates were recorded.

Results: Mean serum AMH was significantly decreased in cystectomy group from $3.1 \pm 0.28$ to $1.8 \pm 0.5 \mathrm{ng} / \mathrm{ml}$ compared with the nonsignificant decrease in combined group from $3.9 \pm 0.27$ to $3.1 \pm 0.4 \mathrm{ng} / \mathrm{inl}$. Also, AFC was significantly decreased in cystectomy group from $4.1 \pm 0.4$ to $2.7 \pm 1.1$ compared with the nonsignificant change in combined group from $3.8 \pm 0.6$ to 4.1 \pm 1.9 . Basal serum levels of FSH and LH did not change in the two groups. Spontaneous pregnancy and recurrence were comparable in both groups.

Conclusion: Combination of partial cystectomy with ultrasound powered ablation yielded better results than complete cystectomy with regard to the ovarian reserve.
\end{abstract}

Key Words: Endometrioma, excision, laparoscopy

Received: 22 February 2018, Accepted: 30 March 2018

Corresponding Author: Hesham Salem, M.D., Department of Obstetrics \& Gynecology, Tanta University, Tanta, Egypt, Tel.: 01223488672,E-mail, hesham_salem@hotmail.com

ISSN: 2090-7265, May 2018, Vol.8, No. 2

\section{INTRODUCTION}

Endometriosis and ovarian endometrioma have been a matter of debate since Sampson's publication of this paper on the pathogenesis of endometriosis in $1925^{[1]}$. The pathogenesis of ovarian endometrioma is a matter of controversy. There are three different theories explaining the pathogenesis : Invagination of the ovarian cortex after accumulation of menstrual blood from nearby endometriotic implants, involvement of ovarian functional cysts and metaplasia of the coelomic tissue ${ }^{[2]}$.

Whether to remove the endometrioma or not is another controversial issue. Some studies recommended surgical removal, while others did not. Both opinions, however, have their justifications ${ }^{[2]}$. Menstrual and extra menstrual pain relief provides a strong justification favoring surgery ${ }^{[3]}$.

Considering the impact of surgery on the ovarian reserve, some studies have argued that surgery at least prevents further destruction of the healthy ovarian cortical tissue induced by the enlarging endometriotic cyst, and thus improves the future fertility ${ }^{[4]}$. Also, with relatively recent availability of IVF, oocyte retrieval can be rather difficult with the presence of the endometrioma. Moreover, there is an increased liability for occurrence of pelvic infection and negative effect on the oocyte quality in case the endometrioma was inadvertently punctured and drained during oocyte retrieval ${ }^{[5]}$. Another reason for favoring surgical removal could be the possible relation between endometrioma and ovarian cancer. As shown by Nyhoj 
et al i.e. ${ }^{[6]}$ the similarity of the etiological factors of the two diseases are related to genetic, hormonal and immunologic reasons. Furthermore, ovarian cancer is more common in patients with infertility which is also a common cause of endometriosis.

On the other hand, other studies do not recommend surgical removal of ovarian endometrioma for two reasons: 1- Having a direct negative impact on the ovarian reserve in case of removing healthy ovarian tissue with excessive surgery. 2- Endometriosis is a disease characterized by a high recurrence rate ${ }^{[8]}$

In spite of the wide preference of laparoscopic surgical treatment of endometrioma, still there is a controversy about the best laparoscopic surgical modality for dealing with endometrioma considering the effect on the ovarian reserve and the possibility of insufficient treatment that leads to early recurrence ${ }^{[8]}$.

In the current study, ovarian reserve markers ; namely, $\mathrm{AMH}$, basal FSH and $\mathrm{LH}$ and AFC are estimated before and after the laparoscopic management of ovarian endometrioma by two different modalities ; complete cystectomy and partial cystectomy combined with US power ablation. This study aimed to identify the modality with less impact on the ovarian reserve with follow up to estimate the effectiveness of each modality in symptoms improvement, spontaneous pregnancy and recurrence rates.

\section{PATIENTS AND METHODS}

This study was conducted at Obstetrics and Gynecology Department in Tanta University Hospital between February 2011 and May 2014. 40 women aged between 20 and 35 years with unilateral or bilateral ovarian endometrioma $>3 \mathrm{~cm}$ and complaining of infertility and/or pelvic pain were included in the study.

The exclusion criteria included patients with body mass index (BMI) more/than $30 \mathrm{~kg} / \mathrm{m} 2$, known or suspected pregnancy and malignancy, patients with pre-operative evidence of low ovarian reserve, patients with high risks for surgical interference and presence of previous hormonal or surgical treatment of endometriosis.

After obtaining an approval of the hospital ethical committee, patients signed on a written consent after being informed of the details of the study.

A complete examination sheet was done for all patients including the demographic data and the symptoms of each patient e.g. infertility, dysmenorrhea, dyschezia and chronic pelvic pain.

Ovarian reserve markers were estimated for all patients. These markers included AMH, basal serum FSH and LH and AFC. Transvaginal ultrasound examination in the proliferative phase was conducted to all patients in order to measure the size and dimensions of endometrioma as well as determining the AFC and to exclude patients with suspected functional and malignant cysts.

The patients were then randomly divided into 2 equal groups each included 20 patients:

Group 1: (cystectomy group): patients treated with laparoscopic complete excision of the endometrioma.

Group 2: (combined group): patients treated with laparoscopic partial excision of the superficial easily dissectible non-firmly adherent part of endometrioma combined by US power ablation of the deep part of it.

Operative laparoscopy was done to all the patients at the proliferative phase of the cycle. Inspection of the whole abdominal cavity was done at first with staging of the endometriosis according to the revised American Society for Reproductive Medicine (ASRM) classification. Adhesiolysis is done to release 1 the ovary if it was found adherent to the surrounding tissue. Anti-mesenteric puncturing of the cysts was done if not spontaneously punctured. This was followed by an aspiration of the materials together with an extension of the incision along and saline irrigation to facilitate the inspection of the interior of the cyst ${ }^{[2]}$.

Complete cystectomy was done by creating a plane between the cyst wall and the adjacent ovarian tissue via hydrodissection. The cyst wall was removed by traction and counter-traction using two atraumatic forceps through the created line of cleavage: hemostasis of the cyst bed with US power coagulation followed by washing the cyst and the pelvis with hot saline ${ }^{[2]}$.

Partial cystectomy was done to patients in the combined group. The portion removed from the cyst was the superficial easily dissectible non-firmly adherent part of endometrioma. The dissection of this part was done using the same principles used in cystectomy. The dissection ended at the site of dense adhesion between the cyst wall and adjacent tissue and/or at the place which has a remarkable bleeding from dissection. The inner wall of the remaining part of the cyst was ablated by US power coagulation, followed by washing the cyst and the pelvis with hot saline. ${ }^{[9]}$ All the excised tissue was sent for histologic examination.

The used US ablation blades in the current study were HARMONIC SYNERGY (®) blades produced by Ethicon United States of America. This study used the HARMONIC SYNERGY® Curved Blade, Hook Blade and Combination Hook Blade. The US generator used was Ethicon Endo-Surgery Generator Gil.

The outcomes of the study were the changes in the 
ovarian reserve markers 6 month after laparoscopic surgery and the rate of spontaneous pregnancy and recurrence.

\section{RESULTS:}

The clinical, demographic and ultrasound data are shown with no significant difference between the two studied groups, as summarized in Table 1. The operative findings are summarized in Table 2 and showed no significant difference between the two studied groups.

Table 1 : Baseline demographic, clinical characteristics and ultrasound findings in the two groups

\begin{tabular}{|c|c|c|c|}
\hline Variable & $\begin{array}{l}\text { Cystectomy } \\
\text { group }(n=20)\end{array}$ & $\begin{array}{c}\text { Combined } \\
\text { group }(\mathrm{n}=20)\end{array}$ & $\begin{array}{c}\mathrm{P} \\
\text { value }\end{array}$ \\
\hline Mean $( \pm$ SE) age; $(y)$ & $29.2 \pm 1.7$ & $30.5 \pm 1.8$ & NS \\
\hline $\begin{array}{l}\text { Mean }( \pm \mathrm{SE}) \text { cycle } \\
\text { length }(\mathrm{d})\end{array}$ & $28.1 \pm 0.4$ & $29.2 \pm 1.1$ & NS \\
\hline BMI (kg/ni2) & $23 \pm 1.9$ & $24 \pm 1.2$ & NS \\
\hline $\begin{array}{l}\text { No. of nulliparous } \\
\text { patients }\end{array}$ & 12 & 14 & NS \\
\hline $\begin{array}{l}\text { No. of patients } \\
\text { with infertility }\end{array}$ & 16 & 15 & NS \\
\hline $\begin{array}{l}\text { No. of patients with } \\
\text { dysmenorrhea }\end{array}$ & 10 & 12 & NS \\
\hline $\begin{array}{l}\text { No. of patients with } \\
\text { dysparcunia }\end{array}$ & 6 & 8 & NS \\
\hline $\begin{array}{l}\text { No. of patients with } \\
\text { chronic pelvic pain }\end{array}$ & 16 & 14 & NS \\
\hline $\begin{array}{l}\text { No. of patients with } \\
\text { dyschezia }\end{array}$ & 12 & 10 & NS \\
\hline $\begin{array}{l}\text { Mean }( \pm \text { SE) diameter } \\
\text { of the cyst }(\mathrm{mm})\end{array}$ & $37.2 \pm 4.1$ & $38.1 \pm 5.4$ & NS \\
\hline $\begin{array}{l}\text { Mean revised } \\
\text { AFS score }\end{array}$ & $42.3 \pm 417$ & $42.3 \pm 4.9 .1$ & NS \\
\hline
\end{tabular}

Note: Values are mean \pm .SE. NS $=$ not significant

The surgical duration ranged from 20 to 30 minutes in combined group and from 30 to 40 minutes in cystectomy group. There was no need to shift from laparoscopy to laparotomy and no complications were encountered in the two groups.
Table 2 : Baseline operative findings in the two groups

\begin{tabular}{lccc}
\hline \multicolumn{1}{c}{ Variable } & $\begin{array}{c}\text { Cystectomy } \\
\text { group (n=20) }\end{array}$ & $\begin{array}{c}\text { Combined } \\
\text { group (n=20) }\end{array}$ & P value \\
\hline $\begin{array}{l}\text { No. of patients } \\
\text { with stage IH }\end{array}$ & 8 & 9 & NS \\
$\begin{array}{l}\text { No. of patients } \\
\text { with stage TV }\end{array}$ & 4 & 3 & NS \\
$\begin{array}{l}\text { No. of } \\
\text { endonictriomas } \\
\text { in right ovarv }\end{array}$ & 11 & 8 & NS \\
$\begin{array}{l}\text { No. of } \\
\text { endometriomas } \\
\text { in left ovary }\end{array}$ & 9 & 12 & NS \\
$\begin{array}{l}\text { Percentage of red } \\
\text { color peritoneal } \\
\text { lesions }\end{array}$ & 79 & 83 & NS \\
$\begin{array}{l}\text { Percentage of } \\
\text { black color } \\
\text { peritoneal lesions }\end{array}$ & 8 & & \\
$\begin{array}{l}\text { Percentage of } \\
\text { white color } \\
\text { peritoneal lesions }\end{array}$ & 17 & & \\
\hline
\end{tabular}

Note: Values are mean \pm .SE. NS $=$ not significant

During the 6 months after laparoscopy, spontaneous pregnancy occurred in 5 cases in the combined group and 4 cases in the cystectomy group. Recurrence of the cyst occurred in 2 cases $(1.0 \%)$ in the combined group and only one case $(0.5 \%)$ in the cystectomy group. The recurrence in the two groups occurred after 6 months of laparoscopy which reflects the absence of under correction.

The statistical analysis of the changes in the levels of the ovarian reserve markers in the two groups before and after laparoscopy is provided in Table 3. It should be noted that the combination of partial cystectomy and bi-polar ablation improved the ovarian responsiveness reflected by the increased AFC but without significant statistical difference. Also, combined modality did not change the AMH which decreased after laparoscopy but without significant statistical difference. Complete cystectomy, on the other hand, significantly decreased AMFI and AFC reflecting negative impact on both ovarian responsiveness and reserve. The basal serum levels of FSH and LH did not show significant statistical difference before and after laparoscopy in the two groups. 
Table 3 : Ovarian reserve markers in the two groups before and after laparoscopy

\begin{tabular}{|c|c|c|c|c|}
\hline & Variable & Before & After & P. value \\
\hline \multirow{4}{*}{$\begin{array}{l}\text { Cystectomy } \\
\text { group }\end{array}$} & AFC & $4.1 \pm 0.4$ & $2.7 \pm 1.1$ & 0.025 \\
\hline & $\begin{array}{l}\text { FSH } \\
(\mathrm{mIU} / \mathrm{mL})\end{array}$ & $6.8 \pm 0.67$ & $\begin{array}{ll}8.4 & \pm \\
1.16 & \end{array}$ & NS \\
\hline & $\begin{array}{l}\mathrm{LH} \\
(\mathrm{mIU} / \mathrm{mL})\end{array}$ & $5.8 \pm 0.45$ & $\begin{array}{ll}7.4 & \pm \\
0.89 & \end{array}$ & NS \\
\hline & $\begin{array}{l}\text { AMH } \\
(\mathrm{ng} / \mathrm{mL})\end{array}$ & $3.1 \pm 0.28$ & $1.8 \pm 1.9$ & 0.022 \\
\hline \multirow{4}{*}{$\begin{array}{l}\text { Combined } \\
\text { group }\end{array}$} & $\mathrm{AFC}$ & $3.8 \pm 0.6$ & $4.1 \pm 1.9$ & NS \\
\hline & $\begin{array}{l}\text { FSH } \\
(\mathrm{mIU} / \mathrm{mL})\end{array}$ & $6.1 \pm 0.43$ & $8.9 \pm 2.43$ & NS \\
\hline & $\begin{array}{l}\mathrm{LH} \\
(\mathrm{mIU} / \mathrm{mL})\end{array}$ & $6.8 \pm 0.67$ & $8.4 \pm 1.16$ & NS \\
\hline & $\begin{array}{l}\text { AMH } \\
(\mathrm{ng} / \mathrm{mL})\end{array}$ & $3.9 \pm 0.27$ & $3.1 \pm 0.4$ & NS \\
\hline
\end{tabular}

Note: Values-are mean \pm SE. $\mathrm{NS}=$ not significant; $\mathrm{AFC}=$ antral follicle count; AMII = anti-Mullerian hormone

\section{DISCUSSION}

Preservation of ovarian reserve is crucial and should be considered before any surgical interference in cases of ovarian endometrioma. The controversy about the best laparoscopic management modality of endometrioma has not been settled ${ }^{[10-13]}$.

The current study attempts to identify the best laparoscopic modality with the least effect on the ovarian reserve. The evaluation of the ovarian reserve in the current study is based on the estimation of the serum level of AMH, basal FSH and LH and AFC.

In a Cochrane review, Hart et al..$^{[3]}$ concluded that a better outcome is obtained from excisional surgery for endometrioma than ablation proved by a good pregnancy rate and a less recurrence rate after excision. He also argued that there is good ovarian response to stimulation after this excisional surgery either for natural pregnancy or for IVF. Hart based his meta-analysis on three randomized trials comparing cystectomy and bipolar ablation without any prospective analysis of the impact of the two techniques on the ovarian reserve.
Var et al. ${ }^{[14]}$ in a randomized controlled trial found a decrease in both AFC and ovarian volume in patients subjected to ovarian laparoscopic than patients subjected to bipolar, ablation. Var also found that the cystectomized ovaries responded poorly to ovulation induction in JVF than ovaries with bipolar ablation.

In contrast to Hart et al. ${ }^{[3]}$ and similar to the study of Var et al. ${ }^{[14]}$, the current study found that cystectomy significantly yielded a negative impact on the ovarian reserve which is fairly shown by the decrease in both the AFC and AMHJ and that partial cystectomy combined with ablation did not change both the AFC and AMH. The release of ovarian cortex from the pressure exerted by the endometrioma without the use of more heat and without the removal of the healthy ovarian tissue adjacent to the capsule, as in cystectomy, may explain the rise of AFC in the combination technique. Moreover, in cystectomy patients, the use of excessive heat to control bleeding especially near the hilus strongly added a negative impact on the ovarian reserve as shown by the significant decrease of AMH.

On the other hand, the current study estimated the levels of the ovarian markers before laparoscopy and also after six months. Hence, this study is radically different from that of Hart's. ${ }^{[3-15,16]}$

The adverse effect of the ablative power energy is the lateral spread of thermal damage and the depth of tissue penetration (i.e. thermal damage to the underlying tissues). This thermal damage effect is greatly nullified by using US power ablation which induces temperature elevations by more than $40^{\circ} \mathrm{C}$ at $1 \mathrm{~mm}$ distance from the blade; while at $2 \mathrm{~mm}$, the temperature elevation did not exceed $6^{\circ} \mathrm{C}$ at all and without any morphological indications of thermal damage at a distance of more than $2 \mathrm{~mm} .{ }^{[17]}$ Using US power ablation transduces a low amount of energy to the surrounding tissues with limitation of the lateral thermal damage and deep penetration because of lower temperatures reached, the thermal injury zone extends to a depth of $50 \mathrm{c} . \mathrm{m}$. and the thermal effect is almost absent at a distance of 100 um. ${ }^{[18]}$.

The spontaneous pregnancy and recurrence rates in the current study were comparable in both used laparoscopic modalities. In addition, pregnancy occurred spontaneously without ovarian stimulation which reflects better physiological monitoring of ovarian function compared to the studies of Var et al. ${ }^{[14]}$ and Hart et al. ${ }^{[3]}$

Similar results to the current study were found by Donnez et al. ${ }^{[4]}$ Brosens et al. ${ }^{[19]}$ and more recently by Pascale et al. ${ }^{[2]}$. These studies concluded that cystectomy is indeed better than ablation in the 
improvement of symptoms but has a negative impact on the ovarian reserve markers. Pascale added that ablative surgery must be considered in cases of recurrent endometriosis for preservation of the ovarian reserve.

The current study showed no significant changes in the serum basal levels of FSH and $\mathrm{LH}$ in the two groups. The serum level of the two hormones increased after the two laparoscopic modalities but without significant statistical difference. This was also noticed by Tsolakidis et al. ${ }^{[20]}$ and Trmellen et al. ${ }^{[21]}$ who stated that the estimation of serum basal levels of FSH and LH showed low sensitivity till the occurrence of significant decrease in the ovarian reserve.

In the current study, the incidence of spontaneous pregnancy was comparable in both groups, 5 patients $(25 \%)$ in combined group and 4 patients $(20 \%)$ in cystectomy group. Recurrence was also comparable in both groups, it was observed in 2 patients $(10 \%)$ in combined group and only in one patient $(0.5 \%)$ in cystectomy group. Recurrence occurred six months after laparoscopy in the three cases indicating the absence of under treatment and the possibility of de-novo appearance of endometrioma. It should be noted, however, that recurrence and spontaneous pregnancy rates were lower in complete cystectomy and this can be explained by the removal of healthy functioning ovarian tissue with the cyst wall and the need to control the bleeding from the cyst bed near the hilus. These two factors are incriminated in decreasing the ovarian function as shown in the study of Jacques et al. ${ }^{[9]}$. The latter study also showed $40 \%$ pregnancy rate in patients who were subjected to the combination technique and recurrence rate is less than $2 \%$, which is close to the results of the current study.

Canis et al. ${ }^{[22]}$ and Marconi et al. ${ }^{[23]}$ found that cystectomy did not affect the ovarian response in IVFtreated cycles, especially if done by expert surgeon with minimal ovarian trauma. But, it should be noted that these two studies did not examine the natural ovarian response after cystectomy but rather after controlled ovarian stimulations, which explains the difference from the current study results.

\section{CONCLUSION}

In conclusion, this study clarified that laparoscopic management of ovarian endometrioma by a combination of partial cystectomy and bi-polar ablation yielded better impact on ovarian reserve than complete cystectomy, in addition, both techniques have a comparable spontaneous pregnancy and recurrence rates. To achieve the advantageous of laparoscopic surgery of ovarian endometrioma, it must be less traumatic and done by experienced hands.

Ovarian endometrioma is a common clinical problem and due to the relevant small number of patients in this study, more designed studies for larger numbers of patients are needed to cover all aspects of this clinical problem.

\section{CONFLICT OF INTEREST}

There are no conflicts of interest

\section{REFERENCES}

1. Sampson JA. Heterotopic or misplaced endometrial tissue. Am J Obstei Gynecol 1925; 10:649-64.

2. Pascale J, Michio K, Olivier D, Jean S, and Jacques D. Surgical treatment of ovarian endometriomas: stale of the art? Fertil Steril 2012; 98: 556-63.

3. Hart RJ, Hickey M, Maouris P and Buckctt W. Excisional surgery versus ablative surgery for ovarian endometriomata. Cochrane Database Syst Rev 2008; 16: CD004992.

4. Donnez J, Nisolle M, Gillet N, Smets $M$, Bassil S and Casanas-Roux F. Large ovarian endometriomas. Hum Rcprod 1996; 11:641-6.

5. Gelbaya TA, Gordts S, D'Hooghe TM, Gergolet $\mathrm{M}$ and'Nardo LG. Management of endometrioma prior to IVF: compliance with ESHRE guidelines. Reprod Biomed Online 2010; 21:325-30.

6. Nyhoj L, Mathiesen R-and Jochumsen KM. Association between endometriosis and ovarian cancer [in Danish]. Ugeskr Laeger 2010; $172: 3336-9$.

7. Aris A. Endometriosis-associated ovarian cancer: a ten-year cohort study of women living in the Estrie Region of Quebec, Canada. J Ovarian Res $2010 ; 3: 2$

8. Somigliana E, Ragni G, Benedetti F, Borroni R, VegettiW and Crosignani P. Does laparoscopic excision of endometriotic ovarian cysts significantly affect ovarian reserve? Insights from IVF cycles. Hum Reprod2003: 18:2450-3.

9. Jacques D, Jean-Christoplie L, Pascale, Olivier $\mathrm{D}$, and Jean s. Laparoscopic management of endometriomas using a combined technique of excisional (cystectomy) and ablative surgery. Ferti Steril 2010; 99:28-32.

10. Dilek U, Pata O, Tataroglu C, Aban M and Dilek 
S. Excision of endometriotic cyst wall may cause. loss of functional ovarian tissue. Fertil SteriI 2006; $85: 758-60$.

11. Aboulghar M and Mansour R. Cuireni status of management of cndomctriumus. Rev Gynueeul Pract 2004; 4:235-41.

12. Alborzi S, Zarei A. Alborzi S and Alborzi M. Management of ovarian endometriomn. Clin Obstei GynecoJ 2006; 49:480-91.

13. Beretta P, Franchi M, Ghezzi F. Busacca M. Zupi E and Boiis P. Randomized clinical trial of two laparoscopic treatments of endoinetriomas: cystectomy versus drainage and coagulation. Fertil Steril I 998; 70:1176-80.

14. Var T, Balioglu S. Tongue E and Kahyaoglu I. The effect, of laparoscopic ovarian cystectomy versus coagulation in bilateral endometriomas on ovarian reserve as determined by antral follicle count: and ovarian volume: a prospective randomized study. Fertil Steril 2011; 95:2247-50.

15. Alborzi S, Momtahan M, Parsanczhad ME, Dehbashi S, Zolghadri J and Alborzi S. A prospective randomized study comparing laparoscopic ovarian cystectomy versus fenestration and coagulation in patients with endometriomas. Fertil Steril 2004; 82:1633-7.

16. Alborzi S, Ravapbakhsh R, Parsanezhad ME, Alborzi M, Alborzi S and ' Dehbashi. S. A comparison of foliicular response of ovaries to ovulation induction after laparoscopic ovarian cystectomy or fenestration and coagulation versus normal ovaries in patients with endometrioma. Fertil Steril 2007; 88:507-9.
17. Koch C, Friedrich T, Metteraich F, Tannapfel A, Reimann FIP, Eichfeld U. Ultrasound Med Biol. 2003Feb;29(2):301-9.

18. Sherman JA and Davies HT. Ultracision: 'the harmonic scalpel and its possible uses in maxillofacial surgery. Br J Oral Maxillofac Surg. 2000 Oct; 38(5):530-2.

19. Brosens IA, Van Ballaer P, Puttemans $P$ and Deprest J. ReconstRiction of the ovary containing, large endoinetriomas by an extraovarian endosurgical technique. Fertil Steril '1996; 66:517-21.

20. Dimitrios Tsolakidis, George' $\mathrm{P}$, Dimitrios V, Dimitrios A, Tryfon T, Anastasia'G, and Basil C. The impact on ovarian reserve after laparoscopic ovarian cystectomy versus three-stage management in patients with-endometriomas: a prospective randomized study Fertil Steril 2010; 94:71-77.

21. Tremellen K.P, Kolo M, Gilmorc A and f.ekamge DN. Anti-Mullei'ian hormone as a marker of ovarian reserve. Aust N Z J Obstet Gynaecol2005; 45:20-4.

22. Canis M, Pouly J, Tamburo S. Mage G, Wattiez $\mathrm{A}$ and Bruhat $\mathrm{M}$. Ovarian response during IVFernbryo transfer cycles after laparoscopic ovarian cystectomy for endometriotic cysts of $>3 \mathrm{~cm}$ in diameter. Mum Reprod 2001; 16:2583-6.

23. Marconi G, Viela M, Quintana R and Sueldo C. Laparoscopic ovarian cystectomy of endometriomas does not affect the ovarian response to gonadotropin stimulation. Fertil Steril. 2002; 87:876-8. 